Brir. J. industr. Med., 1955, 12, 263.

\title{
A CLINICAL STUDY OF A GROUP OF ACCIDENT-PRONE WORKERS *
}

BY

\author{
JAMES A. SMILEY \\ From Short Bros. and Harland Ltd., Belfast
}

One of the many difficulties in the study of accident causation is to keep under detailed medical supervision a group of men exposed to constant risk who provide a sufficiently large number of apparently accident-prone individuals. At the end of 1944 the prospects of continued employment were good. In an area where there was little alternative employment available, $\mathbf{3 0 0}$ men, who in that year had sustained an undue number of accidents, were selected from a total population of 6,450 employed in an aircraft factory. It was felt, as accident proneness might not prove to be a stable quality, that as large a group as possible should be studied.

Eighty-seven men of this group of 300 proved to be prone to accidents during the year 1945 . This paper is concerned with the observations made on them and on a random sample of 100 other men from the same factory.

Schilling (1954) in a brief review states :

" From a number of investigations both Arbous and Kerrich (1951) and Ghiselli and Brown (1948) conclude that the low degree of consistency which exists between the accident rates of individual workmen for separate periods of time may be because the tendency to have accidents is an unstable trait. Much of the evidence of its stability is based on minor accident records. These may be unreliable indicators of accident proneness since some workers get almost every minor injury treated and others do not. Thus, recorded minor accidents may indicate a personal trait which is stable but not necessarily associated with accident proneness."

During the early years of the war in the aircraft factory where this work was done there had been serious labour trouble because of a condition which workers called " alclad poisoning". On investigation it proved to be a low-grade subacute infection of relatively minor (as well as major) cuts and abrasions. As the result of the panic and the measures taken by the medical and supervisory staff in the factory, it is reasonably certain that a high standard of reporting minor accidents was

*The Milroy Lectures delivered before the Royal College of Physicians in London in February, 1955. achieved. In 28 similar factories the average rate of accidents reported per man per year was 1.53 as compared with our rate of $2 \cdot 1$. In the year under review over our whole organization more than 48,000 accidents were recorded in our day-books. Of the cases recorded, 336 developed sepsis during treatment but only one of these men had failed to attend initially when his accident had occurred. It is therefore claimed that extremely few accidents were not recorded.

The accidents studied have been for the most part minor, such as cuts, abrasions, and bruises. The number of accidents which might be classified as serious, e.g., those involving absence from work for two or more days, being just less than $1 \%$ of the total, was insufficient for statistical purposes. That this procedure is legitimate is sustained by the work of Farmer and Chambers (1929) and Greenwood and Woods (1919) who showed that those who had an undue number of minor accidents had also an undue number of major accidents. "This implies that those specially liable had more accidents, both minor and major, than others with a lower degree of liability." (Newbold, 1926). Further, the gravity of an accident is apparently fortuitous so that many peculiarities in the distribution of accidents in any large group of men is common to both major and minor accidents. "Accidents of this kind (trivial) are also important in another respect. Since the cause and effect of an accident are unrelated in magnitude, it is immaterial for the study of certain aspects of causation whether the result of the accident is serious or not, and hence data relating to trivial accidents can, with certain precautions, be used to draw conclusions applicable without modification to accidents generally." (Osborne, Vernon, and Muscio, 1922). These precautions have been taken.

It was considered desirable to estimate whether any particular group of workers was exposed to a greater risk than any other. To obtain a sufficiently large group of certain occupations, the accident 
frequency rates per 100,000 man/hours worked over the whole organization were calculated and found to be approximately similar. No attempt has therefore been made to adjust our figures for infinitesimally small variations in the exposure to risk.

\section{Identification of Accident-prone Group}

Fourteen thousand four hundred and ninetyeight accidents were recorded in the day-books of the main factory. Nine hundred and fourteen accidents incurred by drivers of trucks and other vehicles in inter-factory transport together with a number sustained by employees of building contractors were eliminated because it was known that other accidents incurred by this group were being reported and treated at other centres. Therefore the total number of accidents studied was 13,584 and these were distributed over 6,450 workers.

In Table 1 is shown the observed distribution of accidents. On the assumption that accident causation may be a matter of chance only, the Poisson distribution was calculated. It obviously does not fit so that the chance explanation is unacceptable. It has been shown that the negative binomial distribution (first applied to accidents by Greenwood and Yule) can arise on either of the two hypotheses: (1) Fixed but unequal proneness to accidents of the exposed, and (2) the same initial probabilities for all the exposed but the probability of an accident being increased linearly with the number already sustained. The negative binomial was also calculated as in Table 1, and, although it is an improvement, it clearly does not fit.

Arbous and Kerrich (1951) have shown that to discriminate between these two hypotheses it is necessary to examine the bivariate distribution in two separate periods of exposure to risk. This has not been possible in the present investigation but the weight of all the evidence in this and other studies is in favour of the hypothesis that those exposed to risk have an unequal proneness to accidents.

It will be noticed from the Poisson distribution that no worker in the factory would have incurred 10 or more accidents if they had been distributed by chance only. As all those who had incurred 11 accidents or more had remained in our employment during the period under review, we chose their records for study. These 87 men were exposed under one roof to a risk similar to that of their workmates, and had accidents which we postulate cannot be explained under any hypothesis other than that they had and continued to have a liability to sustain accidents. For purposes of comparison a random sample of 100 men working in the same workshop
TABLE 1

OBSERVED AND EXPECTED DISTRIBUTIONS OF ACCIDENTS

\begin{tabular}{|c|c|c|c|}
\hline Accidents & Observed & Poisson & $\begin{array}{l}\text { Negative } \\
\text { Binomial }\end{array}$ \\
\hline \begin{tabular}{|l}
0 \\
1 \\
2 \\
3 \\
4 \\
5 \\
6 \\
7 \\
8 \\
9 \\
10 \\
11 and more
\end{tabular} & $\begin{array}{r}1,520 \\
1,522 \\
1,483 \\
773 \\
483 \\
203 \\
170 \\
82 \\
71 \\
32 \\
24 \\
87\end{array}$ & $\begin{array}{r}785 \\
1,653 \\
1,741 \\
1,222 \\
644 \\
271 \\
95 \\
29 \\
8 \\
2 \\
= \\
-\end{array}$ & $\begin{array}{r}1,775 \\
1,503 \\
1,086 \\
739 \\
488 \\
316 \\
202 \\
128 \\
81 \\
50 \\
31 \\
51\end{array}$ \\
\hline Total & 6,450 & 6,450 & 6,450 \\
\hline $\begin{array}{l}11 \\
12 \\
13 \\
14 \\
15 \\
16 \\
17 \\
18 \\
19 \\
20 \\
21 \\
22 \\
23 \\
24\end{array}$ & $\begin{array}{r}25 \\
24 \\
9 \\
12 \\
5 \\
6 \\
2 \\
0 \\
0 \\
1 \\
1 \\
1 \\
0 \\
1\end{array}$ & $\begin{array}{l}= \\
= \\
= \\
= \\
= \\
= \\
= \\
=\end{array}$ & $\begin{array}{r}19 \\
12 \\
7 \\
5 \\
3 \\
2 \\
1 \\
1 \\
\end{array}$ \\
\hline Total & 87 & - & $\overline{51}$ \\
\hline
\end{tabular}

was taken by withdrawing their clock numbers from a rotating drum. As the identity of the 87 accidentprone men was not established until the end of the year and as we were observing 300 who from their previous record appeared to be potentially accidentprone, we had the opportunity of making observations on nearly 400 men.

\section{Clinical Methods}

The Sister in charge of the nursing staff had a list of these men, and during the year (according to the exigencies of the situation in the consulting room as well as in the factory) she daily presented one, two, or three for examination. Her method was usually to tell a man when he attended the surgery for any minor purpose, e.g., the dressing of an abrasion, that the doctor wished to see him. Occasionally she summoned a man from his work bench. We deliberately kept each man waiting for some minutes without informing him of the purpose for which he was required and thus excited in those who were not quite indifferent, minor degrees of curiosity or apprehension-according to their temperament. It was thought that by subjecting the men to some degree of emotional stress a latent symptomatology might declare itself more clearly. I was not told to which group each man belonged but sometimes I recognized a man as belonging to the potentially accident-prone group. The correlation of statistical evidence with clinical findings has 
always been difficult-not least with those intangible elements which comprise personality. After much consideration Culpin's classification as described in The Nervous Temperament (Culpin and Smith, 1930) was adopted (see footnote to Table 6). It seemed at the time to be the best for our purposes, for it lent itself to statistical methods of study. Where subjective criteria preponderate over objective, the interviewer has constantly to be on guard lest his standards vary. So the results of classification were repeatedly compared and regularly checked against each other.

\section{Culpin's Grouping}

It is necessary to record briefly how the nervous grouping of each individual was assessed, First of all the general appearance of the man was notedthe presence or absence of furrowed forehead and wide palpebral fissures, the stability or otherwise of the pulse rate and the presence or absence of blushing, together with the demeanour, whether aggressive or unobtrusive. Questions were asked about the man's job, his hobbies, and his general mode of life, and an effort was made to discover whether he was in any degree frustrated by any unreasonable fears or anxieties. For example, one man had been a charge-hand but had requested to be returned to the bench because he did not feel " up to it". He blushed violently when the subject of his request was discussed with him. He stammered slightly. As a fitter he was amongst the best in the factory. He exhibited other symptoms ; e.g., when asked what his reaction would be if summoned by the Personnel Manager, he said that he knew "it would be to get my cards", meaning that he was to be dismissed (classified Group 4). Having enquired into the presence, or absence, of what appeared to be unreasonable fears, I next turned to the field of needless activities-the inability to relax or rest ; and also to learn the reaction to any disturbance of abnormally fixed habits of life. Then, if it had not already come out in conversation, enquiry was made into the question of mood; whether, for example, the workman had alternately depression and normality, the frequency of the alternation and, if possible, the intensity. The attitude of the individual, not only to those in authority, to his equals and his subordinates, but to himself, e.g., whether or not he was well adjusted and had insight, was also taken into account. During the interview, too, his attitude to work and working conditions became manifest, e.g., whether work was satisfying, whether noise, cold, and environmental conditions assumed disproportionate significance. If it had not already emerged in conversation, enquiry was made of the reaction in more general situations, e.g., fear of the dark, of heights, indecision in traffic, and so on.

Sometimes this system was not followed because, when the conversation was initiated, all the information needed for classification came spontaneously from the patient.

The fact that scoring in my control group is not markedly at variance with Culpin's own experience of rather different types, and corresponds very closely to that obtained by Davies and Wilson (1937) in their sample of herniated hospital patients, justifies me in the belief that our standards, subjective as well as objective, were similar and strictly comparable, or that we were all subject to the same errors. It tends to confirm, too, that a fairly uniform set of standards was maintained throughout the investigation.

Culpin's classification has the advantage of allowing us to classify men whose condition could not be considered either grossly abnormal or permanent. Many men would not exhibit symptoms of the anxiety state if the stimulus of anxiety was not great. Their reactions may be almost normal although symptoms are present, because circumstances over which they have little or no control bear heavily on them. The group to which each man was allocated was the one found at the interview during the period when he appeared to the Sister-in-Charge to be accident-prone and was sent to me. On a number of occasions individuals who had been rated as in classification 3,4 , or 5 when seen subsequently, after their particular anxieties had been resolved, would have been down graded by two grades. As an example the case history of a fitter aged 29 is typical. Five years previously his fiancée died. His father, mother, one sister, and two brothers were killed in an air raid on Belfast in 1941. He went to live elsewhere and became engaged to the daughter of his host. His second fiancée died suddenly on March 16,1944, and at first inexplicably. The inquest was adjourned and police enquiries followed. He had six accidents in the first week after this catastrophe. On interview he was restless, agitated, showed marked tremor and stammer. He had some agoraphobia, headache, and slept little. He was disturbed by dreams, the most frequently recurring being that he was sitting near the centre of a huge revolving gramophone disc, the centrifugal force of which was driving him nearer and nearer the circumference until, eventually, when he was flung into space, he awakened trembling, bathed in perspiration. The following week he had five more accidents in three days immediately before the adjourned inquest. 
He was classified in Group 4. He took 10 days' holiday and during the remainder of the year had no more accidents. Later he was classified in Group 2.

There was only one clearly psychotic workman. He had definite persecutory delusions and had obtained numerous transfers from one department to another-perhaps not without reason, for his name was Hess. He had, however, hallucinations and brought me to a gun turret to see his nonexistent tormentors. He was classified Group 5.

\section{Distance from Work}

The factor of fatigue is considered by some to be important in accident causation. The amount of time required to travel to work was chosen as probably more important than the distance from work. No significant difference between control and accident-prone groups, so far as long journeys are concerned, was noted.

The average time spent in travelling, surprisingly, was found to be five minutes less for the accidentprone group than that for the controls $(31.2$ minutes as compared with $36 \cdot 1$ ). A possible explanation for the difference was that among those living within the city boundary there was a greater tendency amongst the accident-prone group to cycle to work.

\section{Lost Time}

When considering the number of days lost each year and noting the large amount of lost time, it should be remembered that in this year there were 350 working days. The average amount of lost time for all causes in the accident-prone group was $\mathbf{7 5 . 2}$ days and in the control group 29.9 days. This corresponds with the experience of Newbold (1926). The great discrepancy here is not fully explained by the time lost as the result of accidents, nor, if the medical certificates issued to account for the absence from work of these accident-prone individuals is scrutinized, is it accounted for by any easily definable clinical entities.

\section{Chronic Organic Lesions}

Chronic organic lesions were revealed during the examinations. Some of these were detected clinically, but some, e.g., peptic ulcers, were suggested only by the history. In no case is peptic ulcer recorded where the diagnosis was not confirmed by test meal and radiograph during the year under review, or by the perforation of an ulcer.

Many of these workpeople, especially in the accident-prone group, complained of " rheumatic pains" but when there was no objective evidence of any lesion, no record was made of them. The erythrocyte sedimentation rate of all those who so complained was estimated and only in one case was it found to be above normal limits. As will later be seen, many of the accident-prone group were working under emotional tension and unfortunately association between this and the complaint of " rheumatism", " fibrositis", and the like was not detected sufficiently early in the investigation for its significance to be determined. Flind and Barber (1945) have described the close association between the neuroses and the incidence of "rheumatic pains". In those cases classified by me as "rheumatism" there was a demonstrable lesion. Migraine and petit mal (one case each) are included under the heading "chronic lesions". This has been done to avoid still further sub-classification although no demonstrable organic lesion existed in either case. Another case was that of an ambitious young fitter who spent all his leisure hours " taking classes at the Tech.". He was tall, thin, active, and blond. He disliked being alone in the dark and on being pressed for a reason said vehemently, "I hate cats". He would think that he would be "on the mat" if sent for by his foreman (a most reasonable man). The difficulty uppermost in his mind, however, was a tension which resulted from an unreasoning desire to be the last to leave his department at the end of the day and at the same time an equally powerful urge to catch the first bus leaving the works so that he would be in time for his evening classes. The conflict was never finally resolved and had to be fought each day. His foreman gave us the information that after locking his box of tools the lad would walk backwards still eyeing it until he was out of the department and would then hurry away, but that frequently he would return once, or more than once, to examine his lock or look at the bench to see if he had packed all his tools-sentiment d'incompletude. This man was classified as an obsessional in Culpin's Group 4. At intervals of about 10 to 12 days he was incapacitated by attacks of migraine which lasted two days, and for that reason his absences are classified under the heading of " chronic".

Another man (known to all but his friends as "Dopey") suffered more from bromide and barbiturate intoxication than petit mal. His nervous group is queried because although he had definite symptoms his intelligence was of a low order and his mental reactions were slow. It was therefore difficult to interview him, but he was classified in Culpin's Group 2.

\section{Acute Organic Lesions}

It was difficult to define what lesions to include in the term "acute". Not all acute lesions are 
completely incapacitating and yet some men will stay away from work for a cause which could be justified, while others, with more acute lesions, will remain at their benches. On the other hand liability to accidents may be affected by such a complaint as a common cold. However, as common colds are not compulsorily reportable and some men stay away while afflicted and others do not, it was thought advisable to record only the more severe acute illnesses, i.e., those necessitating an absence from work of more than seven days and therefore supported by a medical certificate. The most common entries are " boils " and " gastro-enteritis". In those cases where boils are recorded the infection was severe-either a crop of small boils or one very large one-but always sufficient to incapacitate completely for at least seven days. It usually happened that those men were at work while the infection was developing and returned before it had subsided. The cases of gastro-enteritis were not examined bacteriologically, and it might be argued that the diarrhoea was symptomatic of their emotional stresses. Against that is the fact that gastro-enteritis was epidemic in the factory some months before this study was started. Further, none of those affected showed evidence of undue emotional strain in any other way. Our experience was that the victims remained at work until their symptoms drove them home.

All vague diagnoses were excluded from this group, e.g., "fatigue ", " nerves", and " gastritis", usually after communication with the patient's own doctor.

One man was recorded as having an acute organic lesion because he returned to work ten days after an operation for acute appendicitis. No lesion was found. Immediately on his return he had a series of accidents. He might be classified as post-operative debility.

Two cases of defective vision are included in the acute lesions because of their extreme degree, amounting almost to blindness in the absence of correcting lenses. At the time both these men were having their spate of accidents their spectacles had been broken; owing to immediate post-war difficulties, one had to wait seven weeks and the other nine weeks for repairs. The association between their visual defects and their accidents was too obvious to be ignored.

\section{Sweating and Albuminuria}

It has been noted in the routine examinations of accident-prone men that traces of albumin were frequently found in the urine, and that an unusually large number of them showed beads of sweat trickling down the thoracic wall from the axillae. Examinations also showed that their hands were moist with sweat, and their feet were almost invariably cold and clammy. It was decided, therefore, to make special enquiry into these points for the purpose of this investigation. Four cases in which albuminuria was found are not considered in this group because an organic cause was demonstrable, e.g., hypertension or chronic nephritis.

\section{Results}

Table 2 shows that an almost identical percentage of each trade is represented in the accident-prone and control groups. This is evidence that in our particular assembly factory no worker is rendered more liable to accidents than another by reason of the nature of his occupation. It does not mean, of course, that there are no jobs involving a higher degree of risk than others. There are, but they are so relatively few and of such short duration that they are unimportant.

TABLE 2

ALLOCATION OF ACCIDENT-PRONE INTO TRADE GROUP

\begin{tabular}{|c|c|c|c|c|}
\hline Trade & & $\begin{array}{l}\text { No. in } \\
\text { Accident- } \\
\text { prone Group }\end{array}$ & $\begin{array}{c}\% \text { in } \\
\text { Accident- } \\
\text { prone Group }\end{array}$ & $\begin{array}{c}\% \text { in } \\
\text { Control } \\
\text { Group }\end{array}$ \\
\hline $\begin{array}{l}\text { Fitter } \quad \text {. } \\
\text { Riveter . . } \\
\text { S.M.W. . } \\
\text { Labourer.. } \\
\text { Electrician }\end{array}$ & $\begin{array}{l}\ldots \\
\cdots \\
\cdots \\
\cdots\end{array}$ & $\begin{array}{r}47 \\
16 \\
10 \\
9 \\
5\end{array}$ & $\begin{array}{r}53 \\
19 \\
12 \\
10 \\
6\end{array}$ & $\begin{array}{r}52 \\
20 \\
13 \\
9 \\
6\end{array}$ \\
\hline
\end{tabular}

Table 3 shows that almost twice as many of the 26-35 age group are found amongst the accidentprone as amongst the controls. In view of the very small numbers, this may not be significant of itself but is suggestive.

TABLE 3

INCIDENCE OF ACCIDENT-PRONE IN DIFFERENT AGE GROUPS

\begin{tabular}{|c|c|c|c|c|}
\hline Age & Group & $\begin{array}{l}\text { No. in } \\
\text { Accident- } \\
\text { prone Group }\end{array}$ & $\begin{array}{c}\% \text { in } \\
\text { Accident- } \\
\text { prone Group }\end{array}$ & $\begin{array}{l}\% \text { in } \\
\text { Control } \\
\text { Group }\end{array}$ \\
\hline $\begin{array}{l}15-25 \\
26-35 \\
36-45 \\
46-55 \\
56 \text { and }\end{array}$ & $\begin{array}{ll} & \\
\cdots & \end{array}$ & $\begin{array}{r}39 \\
26 \\
14 \\
6 \\
2\end{array}$ & $\begin{array}{r}45 \\
31 \\
16 \\
7 \\
2\end{array}$ & $\begin{array}{r}43 \\
17 \\
23 \\
11 \\
6\end{array}$ \\
\hline
\end{tabular}

Attendance at Medical Department.-The number of times each individual came to the Medical Department for reasons other than accidents was recorded. The average number of times in a year that a worker in the accident-prone group reported was 31. The control average was 13. From these figures and clinical experience it is deduced that the accident-prone do not have such a tendency to be sick as to feel sick or to report sickness 
-probably both. It was found, however, that the accident-prone individuals not only report sickness more often but actually have peptic ulcers and other organic illnesses more frequently than the controls.

It seems clear, therefore, that there are amongst the accident-prone group a considerable number with peptic ulceration, and a smaller (by comparison with the controls) number with other chronic and acute conditions.

If, however, all these are excluded from the calculations, the average number of attendances at the Medical Department is almost twice as high in the accident-prone group as in the control group, and that the same ratio holds true for "lost time". It would appear, therefore, that there is a residuum in the accident-prone group which tends to lose time and report illness without obvious organic cause. In the control group approximately $\mathbf{3 0}$ days (29.96) were lost on the average from all causes in the year, and in the accident-prone 75 days (75.2). If from each group the amount of time lost by accidents incurred at the factory is excluded, 26 days are lost on the average by men in the control group from sickness, while each of the accident-prone lost 55 days.

Organic Illness.-As summarized in Table 4, we find that (1) peptic ulcer occurs seven times more frequently amongst the accident-prone than in the controls, (2) chronic disabilities four times more often, and (3) acute lesions three and a half times more often. If, however, we now deduct the amount of time lost as the result of these conditions there is a residuum of 22.2 days in the accident-prone and 6.1 in the controls either not covered by medical certificate or attributed to a vague symptomatology of short duration. These data are not tabulated because they are not purely objective, and are open to criticism. Further, they may include some malingering.

TABLE 4

INCIDENCE OF ILLNESS IN ACCIDENT-PRONE AND CONTROLS

\begin{tabular}{|c|c|c|c|}
\hline Subjects & $\begin{array}{l}\text { \% with } \\
\text { Peptic } \\
\text { Ulcer }\end{array}$ & $\begin{array}{l}\% \text { with } \\
\text { Other Chronic } \\
\text { Conditions }\end{array}$ & $\begin{array}{l}\% \text { with } \\
\text { Acute Ailments } \\
\text { (more than } \\
1 \text { week) }\end{array}$ \\
\hline $\begin{array}{l}\text { Accident-prone } . . \\
\text { Controls .. } \quad . .\end{array}$ & $\begin{array}{c}15 \cdot 6 \\
2\end{array}$ & $\frac{20 \cdot 4}{5}$ & $\frac{21 \cdot 6}{6}$ \\
\hline
\end{tabular}

It would appear, therefore, that not only peptic ulcers, chronic organic disease, and acute illness are associated with high accident rates, but also a group of other disorders concealed under various ill-defined diagnoses.

Functional Disorders.-As those classified in Groups 0,1 , and 2 merely exhibit what might be regarded as personality traits, but those in the higher groups require some assistance towards mental and emotional adjustment, it will simplify comparison if these groups are aggregated as in Table 5.

TABLE 5

AGGREGATED ANALYSIS OF ACCIDENT-PRONE AND CONTROLS ACCORDING TO CULPIN'S GROUPING

\begin{tabular}{|c|c|c|c|c|c|c|}
\hline Subjects & 0 & 1 & 2 & 3 & 4 & 5 \\
\hline $\begin{array}{l}\text { Accident-prone } . \\
\text { Controls ... }\end{array}$ & \multicolumn{3}{|c|}{$\begin{array}{l}27 \cdot 6 \% \\
92 \%\end{array}$} & \multicolumn{3}{|c|}{$\begin{array}{l}72 \cdot 4 \% \\
8 \%\end{array}$} \\
\hline
\end{tabular}

From this Table and Table 6 it will be seen that nine times as many of the accident-prone are emotionally unstable as the controls, and herein may be found the explanation of the group with the indefinite diagnoses offered in good faith to explain absence from work. These diagnoses vary from " rheumatism" to explain vague non-articular pains to "dyspepsia" for which investigation had found no cause, from " chronic inertia" from one unsympathetic doctor to explain a disinclination to face a temporarily difficult situation in the workshop, to " debility (pseudo)" to account for absence from work which in reality was precipitated by an acute domestic crisis in which the workman was involved but over which he had little control.

TABLE 6 *

DISTRIBUTION OF MEN IN ACCIDENT-PRONE AND CONTROL GROUPS ACCORDING TO CULPIN'S GROUPING

\begin{tabular}{|c|c|c|c|c|c|c|}
\hline Group & 0 & 1 & 2 & 3 & 4 & 5 \\
\hline $\begin{array}{l}\text { Actual number in } \\
\text { accident-prone group }\end{array}$ & 0 & 5 & 19 & 32 & 30 & 1 \\
\hline $\begin{array}{l}\text { Percentages in accident- } \\
\text { prone group. }\end{array}$ & 0 & $5 \cdot 8$ & $21 \cdot 8$ & 36.8 & $34 \cdot 4$ & $1 \cdot 2$ \\
\hline $\begin{array}{l}\text { Actual number in con- } \\
\text { trol group } \ldots\end{array}$ & 8 & 38 & 46 & 5 & 3 & 0 \\
\hline
\end{tabular}

* Culpin's groupings are briefly as follows :

$\mathbf{0}=$ no particular symptoms

$1=$ one or more slight symptoms

$\left.\begin{array}{l}2 \\ 3 \\ 4\end{array}\right\}=$ several symptoms, graded according to severity

5 = symptoms sufficiently severe to require treatment

It may be deduced that difficulty in emotional maladjustment is an associated and potent factor in accident proneness.

If we now examine the " nervous grouping" of all the men with peptic ulcer examined in the course of the investigation we find that without exception all 14 are classified in either Group 3 or 4 -an interesting finding not without relevance to the subject of this study. These results seem to indicate that peptic ulceration is a complication occurring 
in a type constituted with a certain kind of personality-the unduly anxious or emotionally unstable.

The two men in the control group who had peptic ulcers not only scored high in Culpin's classification but they also incurred more than twice as many accidents as the average of their group, which is $2 \cdot 6$. They, too, may be accidentprone although chosen at random as controls, and for statistical reasons excluded from the grossly accident-prone group.

One of the most positive findings in the whole investigation will, however, be seen when those who exhibited albuminuria (without obvious renal damage) and sweating are scrutinized. In the control group seven men at the time of the examination had traces, or more, of albumin in the urine, whereas in the accident-prone group $45 \mathrm{men}$, or $52 \%$, exhibited this sign without obvious organic cause. If we compare those of the accident-prone group in whose urine albumin was inexplicably found with their nervous groupings, as in Table 7 , it will be seen that $91 \%$ fell into the higher groups and $9 \%$ into the lower.

TABLE 7

PATIENTS WITH ALBUMINURIA RELATED TO CULPIN'S GROUPING

\begin{tabular}{|c|c|c|c|c|c|c|}
\hline Culpin's group. . & $\mathbf{0}$ & 1 & 2 & 3 & 4 & 5 \\
\hline \multirow[t]{2}{*}{$\begin{array}{l}\text { No. with albuminuria in } \\
\text { accident-prone group }\end{array}$} & - & - & 4 & 17 & 24 & - \\
\hline & \multicolumn{3}{|c|}{$9 \%$} & \multicolumn{3}{|c|}{$91 \%$} \\
\hline
\end{tabular}

Even if we add the albuminurias found amongst the controls only $15 \%$ fell in the lower group and $85 \%$ in the higher. A glance at Table 7 will establish the importance of this finding, and the conclusion that there is a high degree of correlation between transient albuminuria and emotional instability can scarcely be resisted.

Among the accident-prone an initial desire to pass urine or a difficulty in voiding urine was observed much more frequently than in the controls. Detailed records of this observation were not kept for statistical analysis.

During the examination of the accident-prone in the period of time in which they were having their accidents it was noted that many of them were perspiring freely. Frequently large beads of perspiration could be seen coursing down the thoracic wall from the axillae, and almost invariably that their hands and feet were either quite moist or wet with sweat. The complete absence of sweat on other parts of the body was noteworthy. It was accordingly decided when doing the " set " examinations to record the presence or absence of this phenomenon.
In the control group 11 cases of hyperidrosis were observed, but in the accident-prone group 55 cases were seen, i.e., $11 \%$ of the controls and $63 \%$ of the accident-prone exhibited sweating at the outset of the interview.

If we now compare the men encountered having this sign with their nervous groupings, we get the results shown in Table 8 . Thus there is a clear association between this type of sweating and high scoring in Culpin's groups.

TABLE 8

ASSOCIATION BETWEEN SWEATING AND CULPIN'S GROUPING

\begin{tabular}{ll|c|c|c|c|c|c}
\hline Culpin's group. . &. & 0 & 1 & 2 & 3 & 4 & 5 \\
\hline No. with sweating &.. & - & 13 & - & - & 53 & - \\
\hline & & & $19.5 \%$ & & \multicolumn{3}{|c|}{$80.5 \%$} \\
\hline
\end{tabular}

\section{Summary of Findings}

The grossly accident-prone men on the average lost three times as much time from all causes as the controls. After deducting time lost as the result of accidents, the accident-prone men still lost twice as much time as the controls. The accident-prone men lost more time as the result of both acute and chronic illness. They tended to have peptic ulceration more frequently. Excluding organic illness, both acute and chronic, on the average the accidentprone still lost 22 days as compared with the controls who lost six days as the result of conditions either not covered by medical certificates or diagnosed in vague terms like "fatigue", "neurasthenia", "gastritis", suggesting the absence of organic disease. The accident-prone attended the Medical Department three times more frequently than the controls for causes other than accidents. The travelling time to work of the accident-prone was five minutes less than that of the controls. (This was probably due to a greater tendency amongst the accident-prone living within the city boundary to travel by cycle.)

Seventy-two per cent. of the accident-prone when classified according to Culpin were in the higher group as compared with $8 \%$ of the controls, $63 \%$ of the accident-prone as compared with $11 \%$ of the controls exhibited palmar and plantar sweating, $52 \%$ of the accident-prone and $7 \%$ of the controls exhibited transient albuminuria. Also a temporary deviation from normal function of the bladder (either as frequency or inability to micturate) was observed very much more often in the accidentprone than in the controls. It is shown that amongst the subjects of this survey there is a close association between palmar and plantar sweating and emotional 
instability and between emotional instability and albuminuria.

These results were obtained from a study of a group of men who were grossly accident-prone. It is unlikely that they would be found in such a degree of severity if all degrees of accident-prone individuals had been studied. Further, these results were obtained in men who, if they were not permanently accident-prone, were so constituted that they tended to have recurring bouts of accident proneness. Each one of those individuals who proved to be accident-prone during the year under review had been included in the survey because in the previous year he had had a bad accident record.

\section{Discussion}

Not much reliance can be placed on the statistics relating to acute illnesses. For several reasons they are incomplete or unreliable. The medical certificates issued to account for absence from work were frequently found to be unreliable. All vague diagnoses such as " debility". " nerves", and the like were excluded, and only absences for a period of at least seven days were included. There does not yet appear in the literature any satisfactory way of accurately assessing the importance of acute illness as a factor, if any, in accident proneness. It may be that after a prolonged absence by reason of a serious illness the element of "inexperience" re-enters as a factor even in the case of an experienced tradesman.

Age and Inexperience as Factors. - A consideration of Table 3 does not indicate that youth itself is a factor in accident proneness. Forty-five per cent. in the accident-prone group, as compared with $43 \%$ in the control group, fell into the lowest age group, 15-25. The element of inexperience is eliminated in this survey because recruitment of labour for this factory ceased some months before the investigation was begun. It may be, of course, that within the group itself changes in liability take place, e.g., the boys of 15 years may have a high accident rate, and the young men of 25 years a low rate. Not a sufficiently large number of these ages occurred amongst the accident-prone to justify us in making a comparison from which to draw such a conclusion, but it does seem that inexperience, rather than youth, is the factor, because when inexperience is eliminated, as in this case, we have the same percentage of 15-25s in the accident-prone group as in the control. The investigation even of " inexperience" as a factor in accident proneness is difficult because, when large numbers of inexperienced workers, sufficient for study, are being employed, there is usually also a speeding up of production. It is common ground now, that acci- dents due to inexperience mainly occur during the first few weeks of employment, and rapidly decline thereafter. Farmer (1932) quotes Chaney and Hanna to the effect that accidents are five times more numerous during the first day's work than during the next five, so that during the last six months of the year they were 255 times less frequent than on the first day of the year. It cannot be deduced from Table 3 that because only $2 \%$ over 56 appear in the accident-prone group as compared with $6 \%$ in the control group that the middle-aged and older are less prone. The data are insufficient. Vernon and Bedford (1928) have found that accidents are less frequent, but more severe when they do occur, among the old. What does appear significant, however, is that $31 \%$ of the accidentprone, as compared with $17 \%$ in the controls, occur in the 26-35 age group, and that, of the 26 men in the accident-prone group of this age, 22 fell into the higher nervous classification. It was amongst these men that most of the peptic ulcers occurred.

Threat to Personal Security.-It is impossible to give clinical noies of all the cases examined, but in general it can be said that the stimulus to anxiety in the 25-36 age group was a threat to personal security. One man was under constant suspicion and questioning by the police following the dismissal of his father from the firm for fraudulent conversion ; another, suspected of I.R.A. activities, had been informed that his permit to reside in Northern Ireland was not to be renewed; another (later sentenced) confided to me that he had been concerned, with others, in a series of "breaking and entering" thefts ; but the most common story was of the shortage of housing, of getting married and " living with the wife's people", of quarrels with the parents-in-law, most usually the " mother-inlaw" (" the old man-he's decent, he understands, but the old woman, she's_— ! ") was a constantly recurring theme. But whatever the story, the threat, as it appeared to the workman, was almost always directed against his personal security. Financial difficulties were seldom mentioned.

It would appear, therefore, that age is relatively unimportant of itself but that in this age group, 26-35, falls a high incidence of emotional stress. In the case of the larger number living with their parents-in-law, it would appear that all goes well for a few years after marriage. Difficulties with the old people start only when the family begins to increase in number, and after the novelty of the first grandchild has passed.

Lost Time.-Experience has shown that it is not always feasible by ordinary clinical methods to 
differentiate between organic illness and vague diagnoses such as "dyspepsia", " biliousness", and the like. An attempt was made to do this by clinical examination, together with consultation with the patients' own doctors, who indicated to me the results of hospital investigations. It was by these means that we separated the time lost into the four categories : time lost as the result of (1) accidents, (2) acute illnesses, (3) chronic illnesses, and (4) vague illness or inadequately explained absence.

Newbold (1926) found there was a quite definite positive association between the number of accidents an individual has had and the number of visits made to the Medical Department for minor sickness. She found only a negligible connexion between the total amount of time lost and the incidence of accidents. The experience of this investigation suggests that if only the grossly prone are studied there is a well marked association. This of course is utterly unreliable as a criterion of the amount of sickness or the severity of accidents and no conclusion other than the obvious one can be drawn from my results, viz., that grossly accident-prone people tend to lose more time than others and not necessarily as the result of their accidents. This experience is completely at variance with that of Flanders Dunbar (1943). She found that her accident-prone group had unusually good health records, were seldom off work, and suffered very little from colds or indigestion. It may be that factors were operating in her group which were not present in mine or vice versa but in any event her criteria of accident proneness were less exclusive.

That other factors may be operating is suggested by the report of the Iron and Steel Productivity team which visited the U.S.A. in 1951 (AngloAmerican Council on Productivity, 1953). This team noted that there was a discrepancy in the level of lost-time accidents in the two countries, viz., the accident frequency rate in this country was 32.6 per million man/hours worked compared with 7.2 in the U.S.A. iron and steel trades.

Hill and Trist (1953) approached this problem in an interesting way. In a stable work population they classified all absences from work over a fouryear period into those which were $(a)$ prospectively sanctioned, (b) retrospectively sanctioned, and (c) unsanctioned. They found that those with the highest number of accidents had also the highest number of unsanctioned absences and that "accidents were negatively associated with that form of absence requiring prospective sanction".

It should be borne in mind that during their quite prolonged absence from work from all causes the accident-prone were not exposed to risk, and on the assumption that their proneness to accident was unaltered during this period it is probable that had they remained at work they would have incurred even more accidents. In other words, they were probably even more accident-prone than a simple comparison with the control groups would show.

In discussing the finding of Newbold that there is a positive association between the number of accidents sustained by an individual and the number of times he reported sick, Farmer (1932) writes :

" This relation may in fact be due to a tendency to report both accidents and sickness, which is more marked in some people than in others. On the other hand, it is probable that those who most often report minor sicknesses are in a poorer state of health than others, and so feel the strain of their work more. On account of this they may be more willing to seek relaxation from it by reporting sick."

In view of our finding that there is a considerable amount of emotional instability amongst the accidentprone, it is not unreasonable to suggest that this is partly the reason for their increased tendency to report at the Medical Department, and that their feeling of " unwellness" is psychological in origin. Capel (1944) writes :

"Anxiety states are manifest by unreasonable fear
and anxiety. There is a continuous feeling of anxious
expectation, tcgether with a condition of hyper-
sensitivity to noise, lights and other stimuli, and,
frequently, sleeplessness. Visceral symptoms are com-
mon, being, in many cases, an exaggeration of the
normal physiological concomitants of fear. They
include such things as palpitation, tachycardia, sweat-
ing, precordial pain, shortness of breath, vertigo,
nausea, vomiting, variation of appetite, and diarrhoea.
It is because of these viscera! symptoms that anxiety
states are so frequently misdiagnosed as cases of
organic disease."

In this connexion the work of Flind and Barber (1945) is relevant. They found that $42 \%$ of patients admitted to an R.A.F. special rheumatism centre showed significant psychological disorder. They summarize their discussion as follows :

"A number of patients complained of pain without lesions disclosed on investigation. In speculating about the nature of the pains complained of by these patients, Halliday (1941) has suggested that they are purely symbolic in nature as expressive of a state of mind and are being consciously or unconsciously used by the patient as a protest against the situation in which he finds himself, or as escape from the obligations which are imposed on him by circumstances. Gordon (1940), on the other hand, states that it is a matter for argument whether the pain is symbolic, that is originating exclusively in the sensorium, or whether the patient is using a mild degree of discomfort, consciously or unconsciously, to achieve an object.

"Ellman, Savage, Wittkower, and Rodger (1942) consider that the inhibition of aggressive elements in the personality of many of these patients may result 
in muscular tension felt by the individual as pain and limitation of movement, and erroneously interpreted by the examining doctor as fibrositis.

"The generalized mild aching after a prolonged period of nervous tension is not unknown to many of us, as are also the feelings of fatigue in a similar situation. When the latter, due possibly to some persistent conflict in a predisposed subject, appears too readily and frequently, we have the chief presenting symptom of a neurasthenic state, or fatigue syndrome of psychological origin. In a similar way aching may become readily and frequently induced. On the other hand, another factor, as Gordon (1936) has pointed out, is the possible variation in the individual's threshold for the appreciation of his bodily sensations. It may be that the threshold for the appreciation of such sensations is lowered in some cases of neurosis."

Whatever the explanation it would appear that a certain amount of " rheumatism" is psychogenic and there is a growing body of evidence that many "dyspepsias" have a similar origin (Davies and Wilson, 1937). Tidy (1941) reported that of 2,500 cases admitted to military hospitals for dyspepsia, $35 \%$ were diagnosed as " gastritis (functional dyspepsia)". He indicated that as a representation of its frequency this figure is probably fallacious because a smaller proportion of this group than of peptic ulcer find their way to hospital. All the methods of diagnosis available to a modern hospital, including gastroscopy, failed to reveal a lesion. In the discussion which followed there appeared to be a wide measure of agreement that many, if not all, of these cases were psychogenic in origin. It seems, therefore, that much of the time lost by the accidentprone is due to psychological illness masquerading under the guise of organic disease.

Hill and Trist (1953) noted in this respect " that to the extent to which psychological factors were operating (in sick absences) it was expected that absence due to sickness would be associated with that due to accidents. Such an association was shown to exist". These workers suggest that accidents and sickness may be forms of motivated absence-however unconscious the motivation. On the other hand it is recognized that there are certain accident-prone individuals whose reaction to social stresses is quite different-those who make no complaint of symptoms but who tend to become introspective.

Silverman (1945), discussing the importance of the psychological factor in accident proneness, states :

"There are certain individuals who withdraw, so to speak, from the difficulties of life. They become very shy, timid, and seclusive. They cannot accept responsibility and tend to make excuses for not meeting the requirements of the job. They are individuals who have a tendency to daydream exclusively in order to pretend that they are obtaining the satisfaction which they are unable to get in real life. While daydreaming is a relatively normal phenomenon, particularly in young pecple, it is essentially a characteristic of adolescence and if indulged in excessively beyond this period of life it has an unwholesome effect. Where a worker continued to resort to daydreaming he usually manifests poor self-control and is more readily involved in accidents. His mind is not on what he is doing and he is therefore accident prone."

Again this type of individual has been recognized and, while he often has accidents, he does not fit into the picture of gross accident proneness which came to light in this survey. In a factory where there is continuous repetitive work and therefore opportunities for daydreaming, the picture of the accident-prone individual may be quite a different one.

Organic Illness.-Until Flanders Dunbar (1943) suggested otherwise it has been almost an article of faith that ill health is associated with an increased accident frequency. Many observers have noticed and commented on the association and my own results tend to confirm it. It is not difficult to visualize how toxic and degenerative diseases may adversely affect perceptual or cognitive ability on the one hand and motor control and coordination on the other. It is easy, too, to understand how a relatively minor infection, such as the common cold, can increase accident liability, but the accurate study of the importance of acute illness is difficult because of the variability of the reaction to the illness. One man with boils may remain at work, exposed to accident risks ; another with the same degree of infection may go home and be immune. There are other considerations which, while obvious now, only became clear during the course of this investigation.

It seems more profitable to consider observations which have not previously been recorded in the literature : viz., the greater tendency of the accidentprone $(a)$ to have peptic ulceration, $(b)$ to exhibit transient albuminuria under emotional stress, and (c) under the same emotional stress to excrete sweat with a distribution limited to the palms of the hands, soles of the feet, and, less often, the axillae.

(a) Thirteen of the 87 accident-prone (15.6\%) during the year under review, compared with two out of 100 controls had active peptic ulceration. Some said that they had had ulcers in the past, and some have since developed ulceration, but if they were not proved to have an active lesion during the period studied, by test meal and radiological evidence or by perforation, they are not included. If all who claimed a history of duodenal ulceration were included, the ratio of $7: 1$ would be greatly exceeded. 
In discussion of the relationship of their ulceration to their high degree of accident proneness, these men almost invariably connected their discomfort and pain with an inability to concentrate on the job in hand. This is a perfectly reasonable attitude to adopt, and one has seen too frequently men coming for the dressing of a fresh wound complaining, before they leave the department, of some other painful condition, e.g., toothache due to a dental exposure, not to realize that a constant ache or pain affects industrial efficiency. At the same time one cannot help feeling, after listening to the stories of these men, that either their threshold for pain is lowered or that some other factor is involved, or both. It seems significant that all the men who had peptic ulceration and who were also accident-prone should also be classified high in Culpin's grouping. Over 100 years ago it was postulated that gastric changes may be local manifestations of a disturbed nervous system. Clinicians are ready to accept a neurogenic or psychogenic basis for dyspepsia where no structural change in the intestinal canal can be shown, but many are still less than ready to accept such an explanation for a lesion, which can be readily demonstrated.

Harvey Cushing, however, in 1932 described how, after operating on three cases of tumours in the hypothalamic region, each patient died within a short time of peritonitis following perforation, in the first case of the stomach, in the second of the duodenum, and in the third of the oesophagus. Since he published his work, the association of perforating lesions of the upper alimentary tract with operations in the region of the brain-stem has been clearly recognized. Even before this, however, it was known, and has amply been confirmed by numerous experimenters since, that stimulations of the hypothalamus of animals can cause peptic ulceration. In 1934 Beattie and Sheehan were able to produce ulceration by stimulation of the tuberal region of the hypothalamus provided that the vagi were intact, and later from stimulation of the vagi alone. The evidence, therefore, is in favour of the view that at any rate certain peptic ulcerations may be the result of an abnormal parasympathetic stimulus. Cushing (1932) suggests that as

" the result of spasmodic contraction of its muscular coat, possibly supplemented by local spasm of terminal blood vessels, small areas of ischaemia or haemorrhagic infarct are produced, leaving the overlying mucosa exposed to the digestive effects of its own hyperacid juices".

\section{Riddoch (1938) concludes as follows :}

"As to the well recognised liability of worrying subjects to gastric and duodenal dyspepsias, the close linkage between emotional and vegetative reactions has long been known, and the intimate anatomical connection of their central neural basis in the diencephalon has now been proven."

Davies and Wilson (1937) enquired into 205 cases of peptic ulcer, and found that in $84 \%$ the symptoms began soon after some event affecting the patient's work, or finances, or the health of his family. Only $22 \%$ of a control series with herniae gave a history of any such event preceding their illness. They found, as was mentioned earlier, that a group of 100 ulcer patients, using Culpin's system of scoring, had a significantly high score and showed undue nervous tension long antedating their ulcer symptoms. They conclude that chronic peptic ulcer is an example of the influence of the mind in producing structural change.

Sir William Osler, in 1902, when giving an address before the St. Louis Medical Society (included in An Alabama Student as " A Backwoods Physiologist") told the story of how a young American Army surgeon, by name Beaumont, for years cared for a young French Canadian, Alexis St. Martin, who, following a severe gunshot wound developed a huge gastric fistula. In return for this attention Beaumont was allowed to make observations on the patient's gastric secretions. Amongst the many observations made was that of the "profound influence of mental disturbances on the secretion of the gastric juice and on digestion ". Wolff (1943) has reported on a similar patient that fear and dejection produced pallor of the mucosa with diminished acidity, motility, and response to food. Anxiety and hostility produced hyperaemia with increased acidity and motility. During a fortnight of financial anxiety he noticed that the mucosa was unduly susceptible to the production of erosions by trivial injury. Crohn (1942) states that, "Recurrent psychic trauma may either initiate ulceration or maintain activity in an ulcer already formed." He identified the hypothalamus as not only the coordinating centre for the emotions, but as the dominating centre of the autonomic system, thus controlling the secretion, motility, and vasomotor activity of the alimentary canal. He then proceeds to incriminate the cerebral cortex from which recurrent emotional disturbances emanate and pass to the hypothalamus.

Samson Wright (1952) states that stimulation of the middle nuclei of the hypothalamus produces parasympathetic overaction, e.g., cardiac slowing, increased gastric secretion and motility, and even haemorrhagic lesions of the oesophagus, stomach, or duodenum, leading to fatal perforation.

Draper, Dupertuis, and Caughey (1944) have shown that there is a statistically significant length- 
ening in the average $\mathbf{P}-\mathbf{R}$ interval between men who have peptic ulcer and a control group taken at random. If this is true it would seem to be additional evidence in favour of an association between hypothalamic influence and peptic ulceration.

Now we know that psychic disturbances are commonly seen in patients with lesions involving the hypothalamus. Ranson and Magoun (1939) state :

"With tumours in this region there are frequently seen manic conditions, euphoric states, lively speech, flight of ideas, inclination towards obscenity, untroubled passing off of difficulties with witty references, lively inclinations to move about and occupy oneself, anger accompanied by rude insults and violence of sudden onset and abrupt disappearance."

The main difficulty in interpreting these symptoms is to know whether the lesion is destructive or irritative of the centres involved at the actual time they were being affected. We do know, however, that stimulation of the hypothalamus of experimental animals or the freeing of it from cortical influence causes excitement, and removal of the caudal part of the hypothalamus is necessary to eliminate this excitement. In Korsakoff's syndrome the chief lesions have been found to lie in the hypothalamus, and alterations in personality have resulted from epidemic encephalitis, especially in children. Clinical and experimental evidence both establish that the hypothalamus is the main subcortical integrating central mechanism of the autonomic system, and that it is in some way intimately concerned with the coordination of emotional reactions. It would appear, then, that the relationship of duodenal ulceration with emotional instability may be through the hypothalamus, and as accident proneness, in a certain group at least, is related to both, it, too, may be associated with a condition of the diencephalon, or those parts of the cerebrum or cortico-hypothalamic tracts which influence it.

Albuminuria.-It has been shown that in the special series of examinations of the 87 men involved in this investigation, $52 \%$ of the accidentprone, as compared with $7 \%$ of the controls, exhibited at least a trace of albumin in the urine. That this albuminuria was transient and benign was proved in each case by clinical examination to exclude nephritis and hypertension, and by the microscopic examination and testing of two further specimens, one passed in the morning before rising, and the other shortly before the end of the day shift. The presence of an occasional hyaline cast was not regarded as pathological. It was highly improbable that the albuminuria was what is called physiological, i.e., following heavy exercise, because in the aircraft industry there is little heavy labour. Nor could it have been due to exposure to cold for the factory was adequately heated. Fever and gross circulatory failure were also excluded as causes by clinical examination.

Forty-seven out of 52 of these men were below the age of 35 years, and, most significantly, over $90 \%$ of those in the accident group, or $85 \%$ of all who exhibited the sign, were in the upper of Culpin's groups (Table 7). It must be remembered that when this series of specimens was obtained the men were under some degree of emotional stress.

The variability in the statistics given for the incidence of the condition, even when large numbers of men are examined, is illuminating in itself. Lyall (1941) found it only in $0.55 \%$ among 20,000 young adults entering the Forces, but the figure given by Diehl and McKinlay (1942) for a large group of male students is ten times higher. It would seem, therefore, that the circumstances under which urine was excreted may be of some importance.

Various explanations have been given to account for the phenomenon-dietetic and postural-but it is difficult to accept these as explaining all cases. One has seen this condition frequently in adolescents at school, when they come to the sick bay complaining of headache and seeking to be excused attendance at certain classes for which, enquiry showed, their homework had not been prepared. Attempts to produce it at other times failed, unless one adopted a harsh and intimidating manner. It is difficult to disassociate, in nervous individuals, an emotional response from the results of any manoeuvre to which they may be subjected. The description given by Price (1945) is that "the subject is often an anaemic, weedy youth, with a dull, heavy aspect and a tendency to fainting. The heart is irritable and the blood pressure unstable and fluctuates with change in posture". Here we have a picture of vasomotor instability such as one associates with emotional subjects. Ahronheim (1944) noticed that young airmen between the ages of 17 and 26 who fainted following venepuncture almost invariably had a cloud of albumin in the urine, although previous examination had revealed none. In a series of 1,000 consecutive cases he examined the urine before and after venepuncture. He found that more than half of the men had albumin in the second or both specimens, and after detailed consideration of the other causes he comes to the conclusion that the prime factor in the causation of benign or transient albuminuria is not orthostatic or mechanical but emotional. It is, of course, surprising that such a high percentage of healthy 
young men should exhibit the sign following such a minor psychic trauma as venepuncture. My figure of $52 \%$ was obtained as the result of examining those known to be psychologically poorly adjusted.

It would appear that to explain most readily the relationship of emotional activity and albuminuria we must again turn to the region of the hypothalamus. It has been shown that exposure to cold causes vasoconstriction of the renal blood vessels, which, in turn, results in the appearance of albumin in the urine. Constriction of these vessels as a part of a general vasoconstrictor response may be caused by stimulation of the hypothalamus. This organ, in man, is affected also by emotional activity, and it may thus give rise to the sign. The "small arteries that supply the hypothalamus take origin directly from the circle of Willis" (Ranson and Magoun, 1939). Spontaneous subarachnoid haemorrhage as the result of aneurysm of the circle of Willis is often accompanied by a massive transient albuminuria. In the absence of an authoritative pronouncement, it is not unreasonable to assume that the albuminuria may be the result either of interference with the blood supply of the hypothalamus or of mechanical stimulation by the haemorrhage of the autonomic tracts as they pass from the midbrain.

Disturbances of Bladder Function.--Reference has previously been made to the frequency amongst the accident-prone of two symptoms : (1) The inability to pass urine when requested to do so, and (2) the desire (often with urgency) to micturate. The former is apparently due to spasm of the sphincter vesicae or inhibition of the detrussor muscle-in either case a sympathetic effect; the latter due to spasm of the bladder-a parasympathetic effect. This second is easily provoked in experimental animals by stimulating the posterior nucleus of the hypothalamus. That the accident-prone very much more frequently than the controls exhibited one or other of these symptoms may be of some diagnostic importance. The polyuria associated with emotional stress is frequently assumed to be a diuresis. That this is not so has been demonstrated by the work of O'Connor and Verney $(1942,1945)$. They have actually shown that there is an inhibition of diuresis in the dog in these circumstances. Two types were distinguished : (1) a rapid inhibition due to vasoconstriction in the kidney during emotion; and (2) a slow type due to release of anti-diuretic substance from the neurohypophysis, almost completely abolished by removal of the posterior lobe of the pituitary gland. After denervation of kidneys and suprarenals the slow type occurred consistently in all tests and in all animals but the rapid did not. This phenomenon was observed so constantly that it is actually now being used as one measure of the activity of the hypothalamico-hypophyseal system. The same authors (1946) identify the supra-opticohypophyseal tract as being the one along which emotional stimuli affect the neurohypophysis.

To stress the importance of the hypothalamus as a subcortical emotional centre expressing itself through the autonomic nervous system is not the purpose of this paper, but the understanding of the relationships of the various observations made in the course of this investigation is found most readily by reference to that small mass of nervous tissue.

Sweating.-The recognition of emotional sweating confined chiefly to the palms and soles has long been made-even by the laity. Associated with it are the cold, clammy hands and feet. The expression " cold feet" is directed in certain strata of society to the timid and fearful as a term of opprobrium. That its presence is prima facie evidence of a recognizable degree of emotional tension is part of our thesis. If one is to judge by the paucity of literature, little interest in the subject has been taken outside Japan. Osborne and Cowen (1945) had the opportunity of observing the incidence of " trench feet" (or, as they prefer to call it, " peripheral vasoneuropathy after chilling") in two groups of men fighting under the same wintry conditions in the invasion of Europe. Group A was made up of unselected infantry men : Group B was composed of psychologically selected men for an armoured formation. In general, the men in Group A developed "trench feet", the men in Group B did not.

"The clinical findings suggested that the man prone to psychoneurosis developed a more severe peripheral vasoneuropathy than the man of sound personality and good morale, under equal conditions of exposure to the elements and with the same lack of opportunity for adequate foot hygiene."

In their summary they write :

"It was observed that a history of sweaty hands and feet and a tendency to neurosis were common among soldiers suffering from peripheral vasoneuropathy after exposure to severe cold."

"The findings (of psychiatric examination) suggest that the severity of the foot lesions is related to psychosomatic factors, the man of unstable personality being particularly liable to severe effects from cold. The unstable pre-neurotic has an unstable vasomotor system, and the hypersensitive neuromuscular control of his arterioles may make these vessels more susceptible to trauma from cold." .... "such skin, already 'cold and clammy' must be at a disadvantage when exposed to external chill and dampness."

I am not attempting to suggest that the moistness of the hands of the accident-prone is of itself a 
factor in accident proneness. Rather do I take the view that the sweating of the "perspiratory personality " of Osborne and Cowen is symptomatic only.

Clark, Beattie, Riddoch, and Dott (1938), quote the work of Hasama (1930) as follows :

"Hasama considers that there are two kinds of sweat. The 'cold sweat' which appears when the skin vessels are constricted under severe emotional disturbances due to fright or fear he regards as "sympathetic' in nature. On the other hand, the ' warm sweat' which appears with vasodilatation and can be abolished by atropine is parasympathetic in its nature. The sweat glands have thus a dual innervation corresponding closely to that which has been demonstrated for the salivary glands."

Wilson (1934) is at pains to prove by experimental evidence that the sweat glands are not dually innervated but are supplied anatomically by only sympathetic fibres, although these are cholinergistic.

Yas Kuno (1938), shows that

" active sweat glands are present most densely on the sole, forehead, and palm, somewhat less on the back of the hand, still less on the lumbar region, axillae and the lateral and extensor surfaces of the extremities, and least on the trunk and the flexors and medial surfaces of the extremities".

He shows that "sweating caused by heating inevitably appears all over the body surface and never locally, even when the heat is confined to a small portion of the skin surface, but the palms of the hands and soles of the feet do not conform to this general rule. These parts are those where sweat glands are present most densely, and our experiments proved that in the state of so-called insensible perspiration the amount of water discharged from the skin was distinctly larger at those parts than at any other parts of the body surface. It is peculiar, however, that the perspiration from these parts does not increase at all from ordinary thermal causes ; in other words, the palms and soles do not sweat under high atmospheric temperature which causes a profuse sweating on all remaining parts of the body surface. ... The most adequate cause for this sweating seems, however, to be mental stress".

\section{Lovatt Evans (1945) states :}

"The lower centres for heat loss must be placed in
the medulla and cord, at any rate so far as concerns
control of heat loss by alterations in the blood supply
to the skin, or by the secretion of sweat. The same
is true for heat production arrangements, such as
shivering, vasoconstriction, metabolic changes, etc.
But these lower centres can only function in a coordi-
nated manner when under the higher control of the
hypothalamus."

It would appear that sweating from thermal causes is a reflex act not necessarily involving the higher centres in the nervous system, but that emotional sweating is initiated directly by the hypothalamus as the result of impulses from the cortex.
Why should the palms of the hands and the soles of the feet sweat during emotional stimulus ? Kuno suggests that as in most languages there is a phrase for "spitting on the hands"- an act which often, even in this country, precedes the grasping of an implement, there is a recognition that the additional moisture increases the friction between the hand and the implement. In an emergency (presided over by the hypothalamus) nature supplies this localized moisture by sweating. The value of this physiological response to a threat against one's security would probably have been appreciated more keenly in an earlier stage in the history of our race. Whatever the reason for its presence it is certainly associated as a sign in those accident-prone who have a tendency to neurosis, and who occasionally exhibit a transient albuminuria. A glance at the mechanism of the control leads us to the same meeting place to which we were led by some of our other findings - the hypothalamus.

Ranson and Magoun (1939), in reviewing the work of recent years on this small organ, quote more than $\mathbf{3 0 0}$ different references, many of which appear to contradict quite flatly what has only recently been considered as established fact. It is quite clear that the hypothalamus, to use a phrase of R. L. Stevenson in another context, " is a city not yet habitable by the mind of man". It is generally accepted, however, that it is

" concerned with the integrated control of both the sympathetic and parasympathetic system and the secretion of the posterior lobe (neural division) of the pituitary. It is probably concerned to an important extent with reflex emotional expression and in these reactions it influences the activity of appropriate groups of skeletal muscles" (Samson Wright, 1952).

Biggart (1944), after reviewing the function of this region of the brain with regard to water metabolism, fat metabolism, carbohydrate metabolism, its role in disorders of sex, in temperature regulation, in sleep rhythm, and finally as an occasional factor in the production of peptic ulceration, concludes as follows :

"It will be apparent that the hypothalamus serves as an integrating and coordinating mechanism for many of the functions of the body which are mediated by way of the autonomic nervous or endocrine systems. Often it appears that there is a pressor balanced by a depressor mechanism, and that, in general, one of these tends to be situated in the anterior, the other in the posterior, hypothalamus. This balance is so delicately preserved that we are unaware of its existence, and it is only in disease that the manifold functions of this area have been manifested. The stability of body temperature, the control of body fat, the beautiful balance of the intake and output of water, the respiratory rhythm, the constancy of the heart-beat, the cycle of sleep 
the balance between emotionalism and excessive placidity, the control of sex-all these go to create a fixity of the internal environment of the body, and are integrated, coordinated and maintained by the nervous activities of this region."

That abnormalities of some of these functions commonly occur in psychoneurotic patients is well known, and one wonders whether, in these cases, there is either a disorder of the hypothalamus itself or of its control by the cerebral cortex. It would appear that the latter explanation is the more probable. This in itself greatly adds to the difficulty of further study at present, for the reaction of two humans to the same situation may vary-one may blush and another may exhibit pallor, the pulse rate of one may rise, of the other, fall. Bard (1941), states that :

"The cortex, therefore, probably normally exerts both inhibitory and excitatory effects, either directly on the hypothalamus or on the final paths which it has in common with the hypothalamus. In putting emphasis on the hypothalamus as a source of emotional behaviour, it must not be forgotten that the cerebral cortex, whatever its functional relationship to the hypothalamus may be, enormously increases the number of circumstances which are capable of acting as emotional stimuli."

\section{Conclusion}

Our discussion has centred largely around the hypothalamus and it may be well to consider why this is so. We have seen that the accident-prone are socially maladjusted, that they lose time as a result of complaints which at present are not recognized as having an organic basis, and that under the influence of a relatively minor emotional stimulus they tend to perspire freely on the hands and feet, and, less frequently, to exhibit albuminuria. In addition a significant proportion have peptic ulceration.

It has been shown that disorders of behaviour result from lesions of the hypothalamus. The nature of these disorders is, in some respects, akin to those shown on occasions of uncontrolled anger by the apparently normal. They are not unlike those exhibited in the decorticated animal. It is suggested that the exaggerated emotional response of the psychoneurotic may be due either to stimulation of the hypothalamus by impulses from the cortex, or to a diminution of the inhibitory impulses from that area. We know, too, that the accident-prone complain of symptoms which appear to have no pathology in the organ to which they are attributed. Further, it is now realized that most of these symptoms are really the result of a loss of balance between the sympathetic and parasympathetic systems influenced by abnormal emotional activity, and mediated by the hypothalamic region of the brain. That the localized sweating confined mainly to the hands and feet is emotional in causation is recognized, and that its control is in the diencephalon has been acknowledged. Similarly, local vasomotor instability of the renal vessels, which is the probable cause of the appearance of albumin in the urine, is part of a general vasomotor reaction controlled by the hypothalamus. Finally, lesions in this region have been shown to be associated with peptic ulceration.

We have travelled a long way from the lad at the bench who repeatedly comes for a simple dressing to his wound, but we return. Why does he get these wounds? The psychologist believes that the reason is not carelessness, nor is it chance, but rather a state of mind. Miles and Eyre (1922) recognized three different types of attitude to accidents : (1) the victim felt as if the event were apart from him, (2) he " knew it was going to happen but felt powerless to prevent it ", and (3) the victim felt his mind went momentarily blank. Smith (1943), commenting on these, states: "In all these descriptions there is a recognition after the event of a mental failure to control the situation."

This observation does not entirely explain the mechanism of failure but recent work on "The Relation of Adrenalin to Acetylcholine in the Nervous System" reviewed by Burn (1945) may take us a step further. It is stated that :

"Low concentrations of adrenalin in the nervous system increase the stimulant action of small doses of acetylcholine and higher concentrations of adrenalin antagonise them. These two actions may be seen as two phases in the effect of a single dose. Adrenalin, either injected or liberated by adrenergic nerves, also has various actions on voluntary muscles and nerves. It increases the action of acetylcholine on denervated muscles and it improves neurcmuscular transmission when this is diminished by fatigue. It actually improves transmission along the trunk of a nerve. The transmission, however, may be depressed by maximal doses of adrenalin or by stimulation of the sympathetic system. This depression, occurring as it does after sympathetic stimulation, is possibly the physiological change underlying the condition in which an animal is paralysed by fear."

At the conclusion of his review he writes :

" If the action of acetylcholine in the central nervous system, including the brain, is indeed modified by adrenalin, it is conceivable that this modification is the basis of changes in nervous reaction, and even in behaviour, which occur in emotional states when an abnormal concentration of adrenalin is present."

One cannot resist suggesting that as the accidentprone appear, in the main, to be emotionally unstable, and as the evidence directs our attention to the centre of the autonomic system, the hypothalamus, that under the influence of stimulatory 
and inhibitory impulses from the cerebral cortex, minor imbalances of adrenalin and acetylcholine result. A small overflow of adrenalin might cause not " paralysis by fear" but paresis by anxiety, which, in turn, might show as muscular imbalance of central origin. That muscular incoordination under pressure is a feature of those who score high in Culpin's groups has been demonstrated by Culpin and Smith (1930) as the result of submitting them to tests on the McDougall-Schuster dotting machine and the pursuit meter. The mere fact of submitting a nervous subject to a test of any sort is apt to induce an emotional state, even if of only a minor degree, and this would increase as the test becomes more difficult. If conduction in the nervous system is inhibited by an outpouring of adrenalin it would at least appear possible that, as the result of a delay in impulses eventually reaching the neuromuscular junctions, or of a diminution of their number or strength, muscular incoordination would result. The fact that the whole central nervous system would be involved in the process might account for the passivity of the accident-prone at the actual moment the accident takes place.

It might also explain the commonly held view that the obsessional neurotics (whose response is more on the parasympathetic side than on the sympathetic) tend not to have accidents.

In conclusion it should be stated that the results of this investigation would apply only to those engaged on work of a similar nature to that of the aircraft industry. They would not, for example, apply to road accidents where intelligence seems to be a more important factor.

Further, it is not suggested that chance is entirely eliminated in accident causation. It is probable that, by using more involved statistical methods, a larger number of accident-prone would have been identified, but, even so, the number of accidents sustained by those would probably not have been more than $20 \%$ of the total. Our considerations have almost entirely been related to grossly accidentprone workers.

\section{REFERENCES}

Ahronheim, J. H. (1944). War Med., Chicago, 5, 267.

Anglo-American Council on Productivity (1953). Productivity Team Report on Iron and Steel. London. Cited by Hill, J. M. M., and Trist, E. L. (1953).

Arbous, A. G., and Kerrich, J. E. (1951). Biometrics, 7, 340.

Bard, P. (1941). In Macleod's Physiology in Modern Medicine, 9th ed., p. 197. Mosby, St. Louis.

Beattie, J. and Sheehan, D. (1934). J. Physiol., Lond., 81, 218.

Biggart, J. H. (1944). Med. Press, 212, 166.

Capel, E. H. (1944). In Industrial Medicine, ed. H. Rolleston and A. A. Moncrieff, p. 89. Eyre and Spottiswoode, London.

Clark, W. E. Le Gros, Beattie, J., Riddoch, G., and Dott, N. M. (1938). The Hypothalamus, p. 113. Oliver \& Boyd, Edinburgh.

Crohn, B. B. (1942). Amer. J. dig. Dis., 9, 358.

Culpin, M., and Smith, M. (1930). Rep. industr. Hlth Res. Board, Lond., No. 61 .

Cushing, H.'(1932). Surg. Gynec. Obstet., 55, 1.

Davies, D. T., and Wilson, A. T. M. (1937). Lancet, 2, 1353.

Diehl, H. S., and McKinlay, C. A. (1942). Arch. intern. Med., 49, 45.

Draper, G., Dupertuis, C. W., and Caughey, J. L. (1944). Human Constitution in Clinical Medicine. Harper, New York.

Dunbar, F. (1943). War Med., Chicago, 4, 161.

Ellman, P., Savage, O. A., Wittkower, E., and Rodger, T. F. (1942). Ann. rheum. Dis., 3, 56.

Evans, C. Lovatt (1952). Starling's Principles of Human Physiology, 11 th ed., p. 1064. London.

Farmer, E. (1932). The Causes of Accidents, p. 56. Pitman, London.

Farmer, E. (1932). The Causes of Accidents, p. 56. Pitman, London. and Chambers,
Lond., No. 55 .

Flind, Jond., and Barber, H. S. (1945). Quart. J. Med., 14, 57.

Ghiselli, E. E., and Brown, C. W. (1948). Personnel and Industrial Psychology, McGraw-Hill, New York. Cited by Schilling, R.S. F. (1954).

Gordon, R. G. (1936). Brit. med. J., 2, 1243.

-, (1940). Ann. rheum. Dis., 2, 89.

Greenwood, M., and Woods, H. M. (1919). Rep. industr. Fatigue Res. Board, Lond., No. 4.

Halliday, J. L. (1941). Ann. intern. Med., 15, 666

Hasama, B. (1930). Arch. exp. Path. Pharmak. 153, 257, 291.

Hill, J. M. M., and Trist, E. L. (1953). Hum. Relat., 6, 357.

Hill, J. M. M., and Trist, E. L. (1938). Lancet, 1, 299.

Kuno, Y. (1938). Lancet, 1, 299.
Lyall, A. (1941). Brit. med. J., 2, 113.

Miles, G. H., and Eyre, A. B. B. (1922). J. nat. Inst. industr. Psychol., 1, 132 .

Newbold, E. M. (1926). Rep. industr. Fatigue Res. Board, Lond., No. 34 .

O'Connor, W. J., and Verney E. B. (1942). Quart. J. exp. Physiol., 31, 393 .

,- - (1945). Ibid., 33, 77.

Osborne, E. E., Vernon, H. M., and Muscio, B. (1922). Rep. industr. Fatigue Res. Board, Lond., No. 19.

Osborne, J. W., and Cowen, J. (1945). Lancet, 2, 204.

Price, F. W. (1937). A Textbook of the Practice of Medicine, 5 th ed.,

P. 1292 . Oxford University Press, London.
Ranson, S. W., and Magoun, H. W. (1939). Ergebn. Physiol., 41, 56.

Ranson, S. W., and Magoun, H. W. (1939), Ergebn. Physiol., 41, 56.
Riddoch, G. (1938). In Clark, W. E. Le Gros, Beattie, J., Riddoch, G., and Dott, N. M. The Hypothalamus, p. 113. Oliver \& Boyd. Edinburgh.

Schilling, R. S. F. (1954). Practitioner, 172, 666.

Silverman, B. (1945). J. Canad. med. Ass., 52, 26.

Smith, M. (1945). An Introduction to Industrial Psychology, 3rd ed. p. 189 . Cassell, London.

Tidy, H. L. (1941). Proc. roy. Soc. Med., 34, 411.

Vernon, H. M., and Bedford, T. (1928). Rep. industr. Fatigue Res. Board, Lond., No. 51.

Wilson, W. C. (1934). Brain, 57, 422.

Wolff, H. G. (1943). Science, $98,481$.

Wright, S. (1952). Applied Physiology, 9th ed., p. 716. Oxford University Press, London. 